\title{
Envisioning Complete Streets in California: Redesigning the Southern El Camino Real Corridor in Atascadero
}

\author{
Emma Schoppe \\ Second-year, MCRP.
}

\begin{abstract}
Resulting from a partnership between the CRP department, the City of Atascadero, and San Luis Obispo Council of Governments, the South El Camino Real Urban Design Plan was produced by a collaboration between graduate and an undergraduate students. Emma Schoppe, one of the MCRP students participating in this studio, writes how the plan can transform El Camino Real into a mixed-use, attractive, and walkable multi-modal boulevard.
\end{abstract}

A tascadero is a city located approximately 20 minutes north of San Luis Obispo with a population of 28, 310 (2010 census). In the spring of 2012, the City of Atascadero, in association with the San Luis Obispo Council of Governments (SLOCOG), approached the City and Regional Planning Department at Cal Poly to envision future development at a 1.7 mile stretch of the southern portion of El Camino Real in Atascadero. They wanted a 20-year vision urban design plan for the corridor that reflected the goals and policies of Atascadero's General Plan, SLOCOG's sustainable development recommendations, as well as California's Complete Streets Act of 2008, which required that all cities and counties plan for a well-balanced, connected, safe, and convenient multimodal transportation network.

Faculty Vicente del Rio took the endeavor to both his graduate and undergraduate studios (CRP 553 Project Planning Lab and CRP 203 Urban Design Studio 2). Work began with site assessment and community outreach followed by exploration of concepts and plan development including elements such as circulation, streetscape, and design guidelines as well as specific proposals for a south gateway. While both classes worked collaboratively during all phases, the graduate students concentrated on developing the general corridor plan while the undergraduates focused on development projects for the gateway.

\section{Site Assessment}

To better understand El Camino Real corridor as a cohesive whole, the design team conducted an extensive survey of existing physical conditions. To accurately record current uses and conditions, a number of methods were utilized. The design team met with current planning staff for the City in order to analyze existing zoning and land uses, conduct an observational walk, and survey individual buildings and units facing the corridor.

An Awareness Walk was taken through the project area and revealed limited pedestrian activity and several conflicts between pedestrian and bicycle traffic and vehicular traffic. ${ }^{1}$
Little social activity or reason to linger along the corridor was observed. Landmarks and views from El Camino Real including historic colonial homes and vistas of Chalk and Pine Mountain were noted for aesthetic preservation. Primarily Spanish and Mediterranean architectural and design styles were also noted. Few way-finding signs or markers to add identity or sense of place to El Camino Real left the class unsatisfied from the perspective of the pedestrian.

The design team consequently divided the project into 18 design blocks and sub-units for more in-depth analysis, and conducted an extensive survey of existing physical conditions. Specific elements of each unit were recorded including current land use type, number of parking spaces, predominant architectural features and colors, grades, prominent landscaping features such as large trees, and unique characteristics. Photographs of the units were also included. These block analyses revealed a number of common characteristics along the corridor as well as unique characteristics of each section of the corridor. Common characteristics included high traffic speeds and noise, lack of shading and trees or seating, wide sidewalks, under-utilized street parking, and large setbacks with parking lots dominating frontage.

An analysis of current development conditions utilizing the figure-ground mapping technique helped to better understand current conditions (built-up and open spaces, public and private spaces, parking and circulation) and revealed the relationships of elements composing the existing morphology. ${ }^{2}$

\footnotetext{
${ }^{1}$ An Awareness Walk is a method of analysis used during the first visit to a project site. It allows observers to make an initial assessment of the place's character, qualities, conflicts and major elements such as users, behaviors, visual quality, aesthetics, circulation, land uses, feelings of threat, cleanliness, etc.

${ }^{2}$ A Figure-Ground Map is a graphic method that reveals the twodimensional relationship between two elements of the urban tissue, such as built and un-built space. It is a common method in Urban Morphology, the study of the form of settlements, their composition, and transformations over time.
} 


\section{Design Proposal}

Five distinct districts were identified along the corridor, based on existing conditions and potential development. From north to south these districts are: Plaza District, Village District, New Town District, Warehouse District, and South Gateway District. A specific vision and character was described for each of the five districts.

Several design ideas were recommended for the corridor including recommendation for future development footprints, linkages to the surrounding neighborhoods, pocket parks and improvements to the sidewalks and intersections, public art, and specific architectural interventions. The illustrative design for South El Camino Real revealed its full potential for becoming a pedestrian-friendly, economically viable place with ample public space in which community members can convene.

\section{Streetscape Design}

The design team proposed a number of streetscape improvements that provides innovative solutions for the right-of-way, improves the character and safety of the boulevard without impeding circulation or visibility along El Camino Real.

The proposal included a series of general design standards as well as specific proposals. Among these are: street tree bulbouts, which accommodate parallel parking; street treatments to delineate bike lanes and accent the center turn lane; pedestrian islands at intersections to improve safety and break up the streetscape; small parklets to provide areas of rest and activity for visitors to the corridor in under-utilized street parking spaces; and additional street furniture and lighting to provide cohesiveness and pedestrian experience across the districts.

\section{Design Guidelines}

The design guidelines for private development along El Cami-

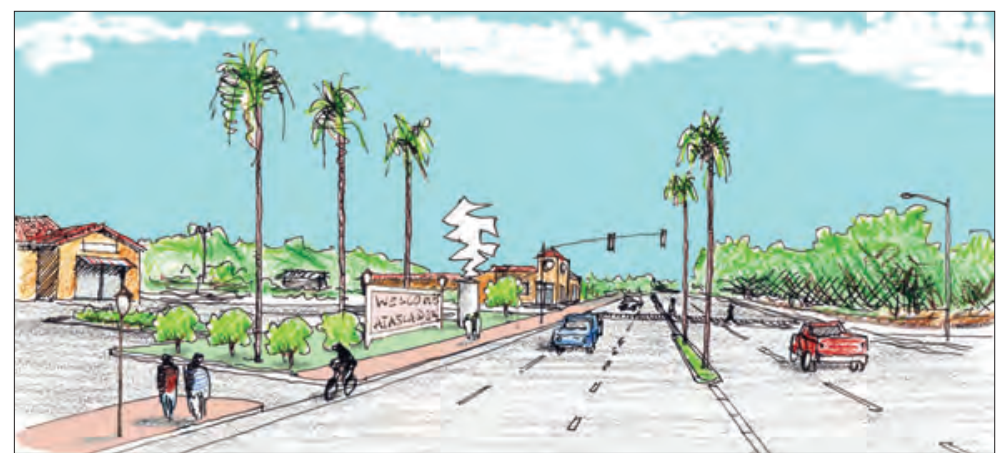

Figure 6: Streetscaping concept for El Camino Real at the major access to downtown from US 101.

no Real were divided into general guidelines and those that were specific to each of the five districts. This was done in order to maintain a coherent overall image while encouraging the creation of a unique character for each district.

General guidelines were categorized according to footprint and setbacks, facades, low impact development, on-premise signage, car-access and on site parking, landscaping and street furniture, screening and permeability, and public art.

\section{South Gateway District}

Given the importance of the area around the intersection of El Camino Real and Santa Rosa Road, and the City's desire to implement a south gateway, this plan established the south gateway entrance as a special district. The proposals for the South Gateway District aim to reconfigure development and establish distinctive character that will mark the entrance to the City from the south, as well as provide a strong connection to the downtown.

Among the specific proposals for the South Gateway District were elements such as a roundabout with a monument for the
Figure 5: Development concept for the proposed "Village District" of El Camino Real.

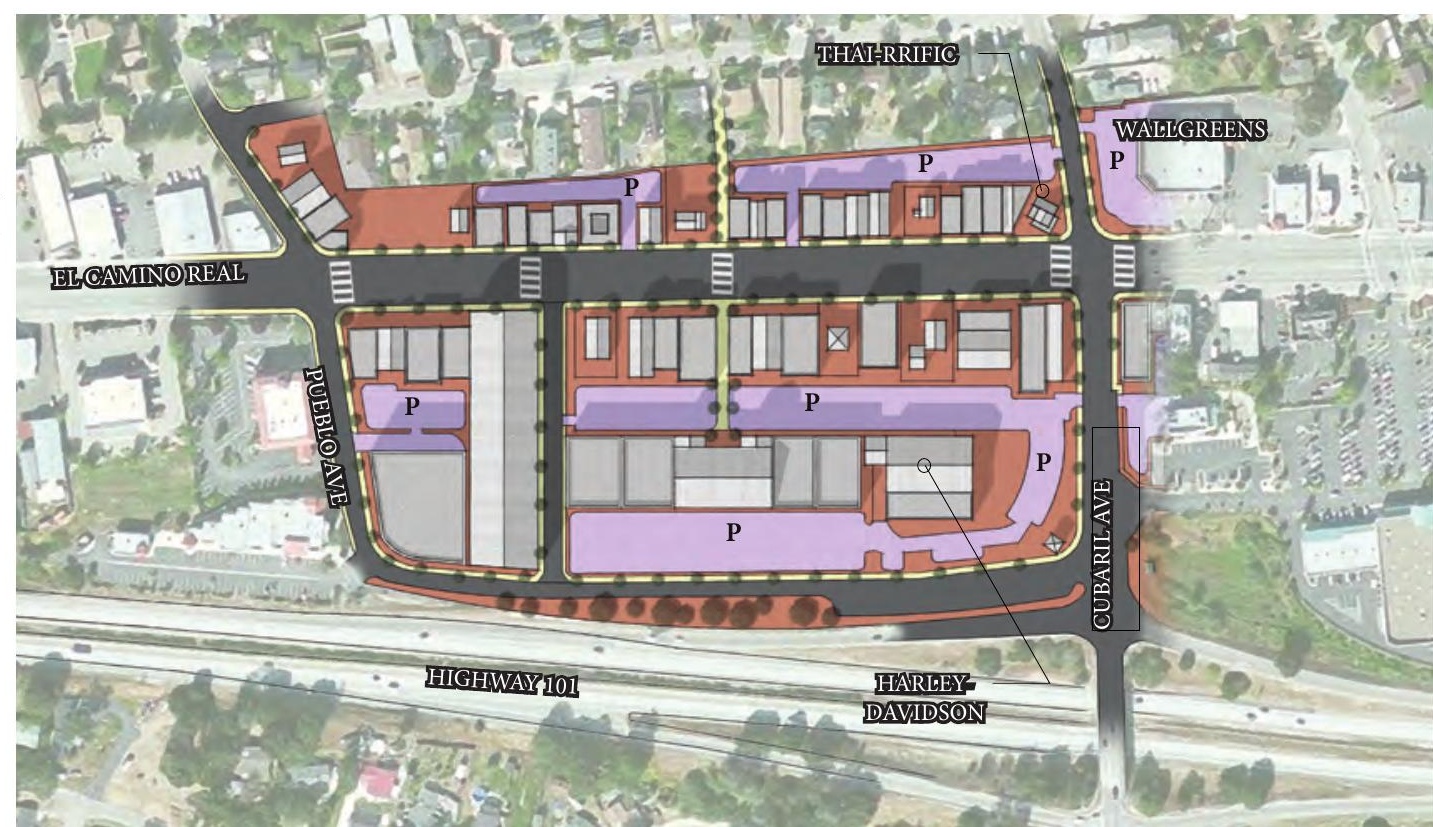



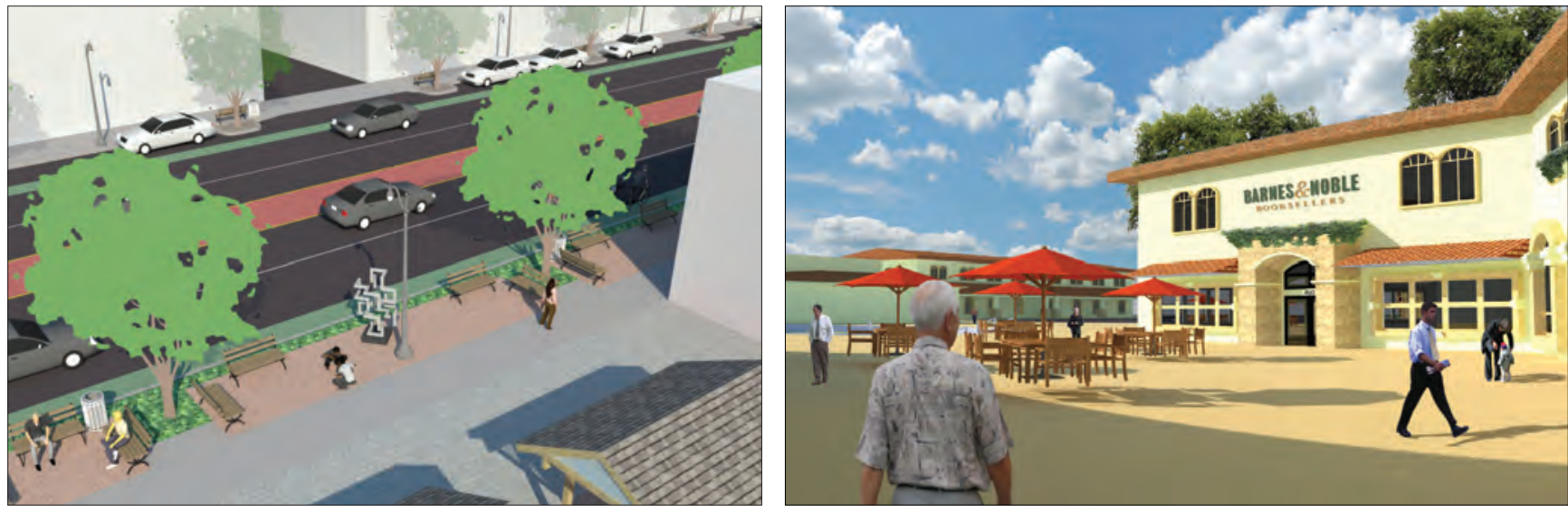

Figures 7 \& 8: Concept for pocket-parks and streetscaping along El Camino Real, and one of the development proposals for a "South Gateway District".

El Camino Real/Santa Rosa intersection as well as the reconfiguration of development around it, improvements to the bridge over Highway 101 to include sidewalks on both sides and bike lanes, a linear park along the creek connecting El Camino Real to the golf course, a new office/commercial park, a new mixeduse development, and several new parks and plazas with fountains, kiosks, and seating.

\section{Final Remarks}

Pedagogically, the experience revealed that collaborations between undergraduate and graduate studios are possible and bring positive results: students learn from each other and the amount and quality of work is expanded. However, when classes are scheduled at different times there are drawbacks to communications that require student "champions" who are available to visit each other's class and help coordinate the work. The final South El Camino Real Corridor Urban Design Plan is a comprehensive document revealing a vision for the future development of Atascadero that reflects the city and the com- munity desires as well as the market potential for the area. It is exemplary of the goals outlined in California's Complete Streets Act, embodying safer streets for all modes of transportation in order to achieve positive social and economic resilience.

At the end of the quarter the students presented the plan to Atascadero's Design Review Committee who provided highpraise and constructive feedback for the students' work. The plan's design concepts and ideas can influence future development along the corridor, therefore enhancing the community of Atascadero. The document will contribute to collaborative grant seeking for implementation of specific projects by Atascadero's planning department and SLOCOG.

Envisioning future development along Atascadero's El Camino Real and translating it into a specific plan document provided valuable, real world experience for both graduate and undergraduate students. The process exposed them to the urban design process along with the unexpected challenges of working with a real community, problem-solving, and team work.

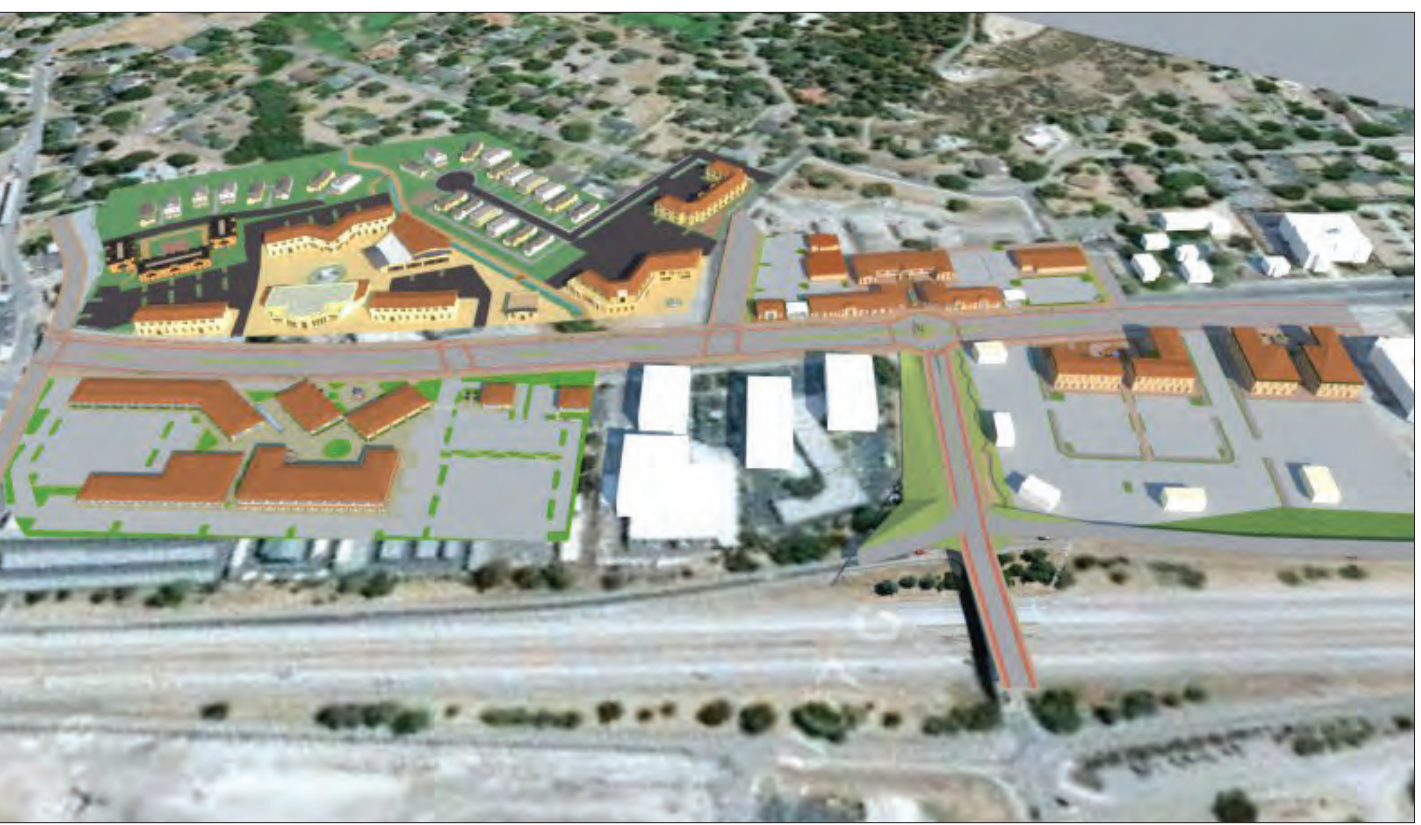

Figure 9: SketchUp model showing the compiled proposals for a "South Gateway District" and a redesigned bridge over US 101. 